Anuario da Facultade de Dereito da Universidade da Coruña

Vol. 23 (2019), pp. 488-491

ISSNe: 2530-6324 || ISSN: 1138-039X

DOI: https://doi.org/10.17979/afdudc.2019.23.0.6035

\title{
IN MEMORIAM, GONZALO DIÉGUEZ CUERVO
}

\author{
JESÚS MARTÍNEZ GIRÓN \\ Catedrático de Derecho del Trabajo \\ Facultad de Derecho-Universidad de A Coruña
}

En la primavera del pasado curso académico 2018-2019, falleció en Santiago de Compostela mi maestro, el profesor Gonzalo DIÉGUEZ, catedrático que fue de Derecho del Trabajo en la Facultad de Derecho de la Universidad compostelana, durante treinta años. Hijo de militar destinado en Galicia, cursó con brillantez la carrera de Derecho en la propia Universidad de Santiago, certificando esta excelencia estudiantil suya el hecho de haber culminado la licenciatura con premio extraordinario. En aquellos años, todavía existía en provincias la inercia y el prejuicio de tener que ir a doctorarse a Madrid, a la Universidad «central», a pesar de que esta Universidad había perdido formalmente el monopolio del doctorado desde mediados de la década de los años cincuenta del siglo pasado. Allí, entró en contacto mi maestro con el profesor don Gaspar BAYÓN CHACÓN, quien fue primer catedrático de Derecho del Trabajo de la Facultad de Derecho de la Universidad Complutense. Cabe imaginarse a don Gaspar abrumado, al recibir requerimientos de potenciales doctorandos provenientes de todas partes de España. En el caso concreto del profesor DIÉGUEZ, resolvió el asunto enviándole a doctorarse a la Universidad de Bolonia, al Colegio de San Clemente de los Españoles, adscrito secularmente a dicha Universidad italiana. Me contaba mi maestro que sus dos años de estancia en Italia fueron intensamente felices, aun cuando el tema de tesis que le había asignado don Gaspar BAYÓN, sobre las relaciones laborales en la agricultura, no le entusiasmase nada. Ya de vuelta en España, con su tesis doctoral concluida, defendida y premiada, acabó trabando relación con el profesor don Manuel ALONSO OLEA, cabeza de la escuela académica contrapuesta a la de don Gaspar BAYÓN, quien era por aquel entonces Presidente del Tribunal Central de Trabajo y catedrático de la Universidad de Sevilla, aunque luego acabaría ocupando la segunda cátedra de Derecho del Trabajo de la Facultad de Derecho de la citada Universidad madrileña. El profesor DIÉGUEZ siempre reconoció a don Manuel como su verdadero maestro (o si se quiere, su «protector») efectivo, fortaleciéndose la relación entre ambos durante los largos años dedicados por mi maestro a la preparación de sus oposiciones a cátedras.

La preparación en cuestión tuvo lugar en la Facultad de Derecho de la Universidad de Navarra, donde el profesor DIÉGUEZ fue contratado como profesor de Derecho del Trabajo. Según me contaba, fueron años de trabajo duro, concentrado sobre todo en la publicación de lo que entonces más curricularmente brillaba, que era la publicación de monografías. Acabé leyendo luego, como es lógico, todo cuanto mi maestro había publicado hasta que le conocí, creyendo de justicia que merecen ahora ser especialmente recordados tres libros suyos de aquellos lejanos años. Ante todo, su 
traducción del Derecho de los Sindicatos de Harry SAMUELS, con un bellísimo (por muy artísticamente concebido y acabado) estudio preliminar, totalmente en línea con lo que entonces publicaba don Manuel ALONSO OLEA, sobre Derecho comparado del Trabajo. También, su libro sobre Responsabilidad directa de las prestaciones de seguridad social (Régimen General), repetidamente citado todavía hoy (a pesar de haber sido publicado hace más de cincuenta años), para recordar que la delimitación jurídica y la dogmática del concepto de «beneficiario» de prestaciones de seguridad social se encuentran primorosamente aclaradas en dicha monografía estupenda. Y por último, Orden público y conflictos colectivos (1976), su trabajo de firma en las oposiciones en que obtuvo plaza de profesor agregado de cátedra en la Facultad de Derecho de la Universidad de Salamanca. Eran tiempos que poco tenían que ver con los actuales, desde el punto de vista universitario. Y ello, porque había muy pocas Universidades públicas, porque se dotaban presupuestariamente (siempre con carácter centralizado) muy pocas plazas de profesor agregado y de catedrático, y porque los concursos para cubrirlas resultaban ser especialmente duros e, incluso, dramáticos (con multitud de concursantes, que tenían el deber de «trincarse» entre ellos, acumulándose tensión por causa del hecho de tener que superar hasta seis ejercicios competitivos, al modo de una verdadera carrera de fondo y de vallas). Tras varios cursos académicos en Salamanca, acabó saliendo a concurso entre profesores agregados la cátedra de Derecho del Trabajo de la Universidad de Santiago de Compostela, que mi maestro ganó (por cierto, tras un concurso muy reñido, pues también pretendía la misma cátedra un colega nuestro luego muy notorio de la escuela de don Gaspar BAYÓN, que acabaría siendo reconocido como «padre» científico de la ley laboral española más emblemática, esto es, el Estatuto de los Trabajadores), dándole el placet un tribunal, tranquilizadoramente presidido para mi maestro por don Manuel ALONSO OLEA.

En la Facultad de Derecho de la Universidad de Santiago, el profesor DIÉGUEZ se estrenó como catedrático en el curso académico 1976-1977. A mí me explicó la disciplina en el curso inmediatamente subsiguiente (dando clase sentado siempre tras la mesa, siempre fumando, como entonces era moneda corriente en nuestras aulas universitarias, y siempre de once y cuarto a doce de la mañana, tres días a la semana, de mediados de octubre a finales de abril). Tras aceptar dirigirme la tesis, me propuso al Rector como profesor ayudante suyo, en 1980, sin necesidad de concurso de méritos de ningún tipo. Evidentemente, eran otros tiempos (los anteriores a la Ley de Reforma Universitaria de 1983), en los que la cátedra no era como hoy simplemente un puesto de trabajo (nivel 29, de la RPT de la Universidad), sino un auténtico órgano (y desde el punto de vista académico, el órgano más importante) de la estructura universitaria. En lo científico, le recuerdo — en un primer momento- escribiendo cosas para publicar en sedes abiertas sólo a los pocos catedráticos universitarios de aquel momento, muchas de ellas coordinadas o dirigidas por don Manuel ALONSO OLEA. Y luego —a partir de 1984-, totalmente concentrado en lo que mi maestro acabaría considerando su magnum opus doctrinal, esto es, su manual de Derecho del Trabajo, que llegó a alcanzar hasta cuatro ediciones con el título Lecciones de Derecho del Trabajo, y otras dos más (la última, aparecida en 2003), pero ya con el rótulo más sencillo y rotundo de Derecho del Trabajo. Se sentía especialmente orgulloso de este «hijo» científico suyo, pues — como tantas veces me comentó- consideraba el manual el libro universitario por antonomasia, y su elaboración un deber indisolublemente ligado a la mejor docencia por los universitarios, así como un auténtico reto, al tener que verse obligado a arriesgar allí sus propias opiniones sobre prácticamente todas las cuestiones debatidas de nuestra ciencia. Lo puse de relieve en una recensión que le hice 
al volumen primero de sus Lecciones, publicada en 1984, poco después de leída mi tesis doctoral.

Aunque venga calificando al profesor DIÉGUEZ de maestro, fue (con frase feliz de don Manuel ALONSO OLEA, que hablaba incluso de la existencia de maestros al cubo) un auténtico maestro al cuadrado, al haberlo sido también de otros maestros universitarios. Durante los treinta años que sirvió como docente e investigador en la Universidad de Santiago, formó como catedráticos a tres discípulos suyos, que ahora todavía servimos en las Universidades de A Coruña, Santiago de Compostela y Vigo. Todo el tiempo que pasé con él en la Facultad de Derecho de la Universidad de Santiago, hasta que accedí a la cátedra en mi alma mater coruñesa, lo recuerdo como un conjunto de años especialmente feliz. Por aquel entonces, iba todo muy despacio, resultaba todo bastante previsible, y además — por encima de todo—, nada había parecido al yugo esclavizante de la actual burocracia universitaria. Hablábamos mucho especialmente por las tardes, también de sus hobbies extrajurídicos (como la ópera italiana o la pintura impresionista francesa; por cierto, él era un gran artista y, sobre todo, un gran retratista, certificándolo así su retrato de cuerpo entero de Margarita PAIS FERRÍN, su mujer, que colgaba en el salón de su casa), e incluso, de cosas y asuntos religiosos (a pesar de considerarme a mí, según decía con algo de sarcasmo, un poco «hereje»). Yo generalmente le pasaba todo lo que escribía antes de mandar a publicarlo, y tengo que reconocer ahora que su «censura» me ayudó, en ocasiones, a evitar muchas meteduras juveniles de pata. Como maestro, además, siempre peleó a muerte por sus discípulos. Lo demostró cumplidamente en el caso de la cátedra de la Universidad de Vigo, cuyo tribunal juzgador no integraba, pero en el que su decidida apuesta por el discípulo suyo que la ganó le llevó incluso a tener que prescindir de los que podrían considerarse como miramientos «de escuela», usualmente tan apremiantes (me lo comentó, en su día, don Manuel ALONSO OLEA, después de poner de relieve que yo me encontraba «au dessus de la melée», en dicho asunto controvertido y dramático, si mirado desde fuera de Galicia).

Tras su jubilación administrativa como catedrático de la Universidad de Santiago, cumplimos con el deber de estricta justicia universitaria de publicarle y dedicarle un Liber amicorum. Se tituló El conflicto colectivo y la huelga. Estudios en homenaje al Profesor Gonzalo Diéguez, habiéndoselo ofrecido en un acto sorpresa, celebrado en 2008, en la Facultad de Derecho de Ourense de la Universidad de Vigo. Colaboramos en él dieciséis catedráticos españoles de la disciplina, junto con un último discípulo suyo chileno, de la Facultad de Derecho de la Universidad de Los Andes. Hablando con él en privado ese mismo día, llegó a emocionarse, y me escribió luego una larguísima carta manuscrita, que conservo, en la que recensionaba crítica y cariñosamente, con su estilo de siempre, mis dos aportaciones al Festschrift en cuestión (una introductoria, y la otra sobre el tratamiento del tópico en los manuales españoles de Derecho del Trabajo, incluido el manual de mi maestro). Desde ese día y hasta su fallecimiento, nuestra relación fue siempre tranquila y, sobre todo, madura. Yo le mandaba algunas de las cosas que publicaba, que creía que podrían interesarle, y él hacía exactamente lo mismo conmigo. Aunque le traje aquí, a nuestra Universidad, para que conociese al brillante laboralismo universitario coruñés, nuestra relación acabó siendo más fluida desde que aprendió a manejarse con el correo electrónico (en sus mensajes, me preguntaba siempre por Alberto ARUFE VARELA, para él «Arufe», también ahora catedrático; por cierto, a mí siempre me llamaba «Girón», y sólo en estos últimos años lo hacía usando mi nombre de pila). Nunca dejó de publicar 
(especialmente, en la Revista Española de Derecho del Trabajo, que había fundado y dirigido hasta su fallecimiento, en 2003, don Manuel ALONSO OLEA). El hilo conductor de estas últimas publicaciones suyas, tan rabiosamente anticapitalistas y tan despegadas del Derecho positivo actual (no, en cambio, de los viejos códigos continentales europeos, sobre todo franceses y alemanes), era muy propio no sólo de un catedrático senior, sino también y sobre todo de un verdadero catedrático «águila». Deberían merecer un análisis más profundo y sistemático, que me comprometo aquí a realizar, como un acto más de homenaje a quien más decisivamente contribuyó a hacer posible lo que ha sido mi vida universitaria — tan feliz- en estos últimos veintiocho años. 